\title{
TRABAJO, CLASE Y PRÁCTICAS POLICIALES EN LAS COMISARÍAS DE LA CIUDAD DE MÉXICO, 1870-1920
}

\author{
Diego Pulido Esteva \\ Instituto Nacional de Antropología e Historia
}

Un sueldo del Estado no alcanza ni para comprar el té y el azúcar. Si ha habido un poco de soborno $[\ldots]$ ha sido en pequeñeces. Por ejemplo $[\ldots]$ en cosas para la mesa $[\ldots]$ o en algún que otro vestido.

Nicolai V. Gogol, El inspector, 1836

“ garrado al mísero empleo en la alternativa de pegarse un 1 tiro", acucioso lector de Los miserables, puntual en su horario laboral pero desprolijo en su desempeño, admirador de la ley, pero inescrupuloso u omiso al hacerla cumplir, el protagonista de La camada (1912) trabaja como practicante supernumerario de la $5^{\mathrm{a}}$ comisaría. Escrita por Salvador Quevedo y Zubieta - quien probablemente vertió algo de su biografía en aquel practicante-, legó en esa novela una detallada representación de las oficinas policiales de la ciudad de México. Las rutinas de los escribientes, la rusticidad de los gendarmes, la ineficacia

Fecha de recepción: 21 de noviembre de 2017

Fecha de aceptación: 11 de abril de 2018 
de los médicos en sus peritajes, la prepotencia de los rangos altos, así como la generalizada intemperancia y corrupción, forman parte de una imagen de la policía que acabaría por estereotiparse. Si bien numerosas, entre las principales frustraciones del personaje se encuentra la dificultad de ascender en el escalafón burocrático y, por lo tanto, la imposibilidad de mejorar su posición social.

Más allá de esta representación novelístico-autobiográfica, el estudio histórico de la policía rara vez ha confrontado esta institución con identidades de clase ni la ha diseccionado internamente como un conjunto de actores sociales. Por tal motivo, este artículo alberga el doble propósito de dar rostro social a las burocracias en el proceso de formación del Estado mexicano y, al mismo tiempo, abonar a la historia social de las policías modernas atendiendo tanto sus aspectos formales como a sus prácticas. Para revitalizar ambos campos de estudio, se describen las condiciones de trabajo en las comisarías, se identifica socialmente a los empleados de las mismas, se analiza el movimiento de personal, la rotación de puestos, sus salarios y, por último, las prácticas que se efectuaban en esos nodos del poder policial. En esencia, las comisarías convocaban a un número de empleados reducido pero creciente, burocráticamente complejo y, desde luego, dinámico con respecto a escalafones, rutinas laborales y transformaciones que experimentaron las oficinas públicas de la época porfiriana a la posrevolucionaria.

A pesar de que se han considerado los vínculos con la criminalidad urbana y la administración de justicia, la historiografía sobre las policías en México tiene pendiente mostrar formas de trabajo diversificadas, jerarquizadas y crecientemente especializadas que ocurrieron dentro de esa institución. Es verdad que los miembros de la policía capitalina eran empleados públicos, pero éstos se diferenciaban según el lugar que ocupaban en el escalafón. Los perfiles sociales variaban según el tipo de trabajo que desempeñaban, esto es, si eran parte del personal de 
oficina o bien si se trataba de gendarmes enrolados en una fuerza pública que se desplegaba, fundamentalmente, en las calles. Por tal motivo, la policía permite observar la conformación social del sector terciario - tan definitorio de la sociedad del siglo $\mathrm{xx}$ como desatendido por el escrutinio histórico del pasado mexicano-. Se trata, entonces, de una instancia que permite conocer ámbitos laborales burocratizados, pues en la medida en que los servicios policiales pretendieron modernizarse, el personal de oficina se ensanchó de manera sensible. En pocas palabras, este texto reconoce la heterogeneidad social de la policía, instancia de la cual tenemos una imagen todavía monolítica a pesar de estudios recientes. ${ }^{1}$

\section{DE POLICÍAS A POLICÍAS}

Durante el último tercio del siglo xix se llevó a cabo la reorganización de la policía urbana en la capital mexicana. Esta transformación fue impulsada por la creciente centralidad del poder Ejecutivo sobre un rubro que se había mantenido bajo el cobijo del ayuntamiento. Sin dejar de ser nominalmente municipal, se diseñó un sistema policial formado, por una parte, por un brazo burocrático compuesto por la Inspección General de Policía y las comisarías. Por otra, se conformaba de una fuerza armada jerarquizada, uniformada y desplegada en la ciudad para velar por el cumplimiento de los reglamentos, prevenir el desorden y detener a presuntos delincuentes.

Es cierto que el término "comisario" hunde sus raíces en la Francia de antiguo régimen, como también lo es que el hecho de haber sido una figura administrativa notoriamente itinerante espacial y temporalmente. Se trata de un cargo adaptado con ciertos matices en diversas latitudes de América Latina,

\footnotetext{
${ }^{1}$ Agradezco el apoyo que recibí de Ámbar Espinosa de los Monteros en la revisión documental.
} 
socorrido y consolidado durante el siglo XIX para gestionar de forma centralizada y articulada la policía urbana. ${ }^{2}$ De una figura relativamente aislada se transformó en una dependencia que se caracterizó por mantener una posición umbral entre la justicia y la policía, aspecto que hizo de este cargo un continuo semillero de conflictos. También es verdad que tuvo una importante trashumancia en el continente americano, donde "adquirió una ontología incierta, tensionada entre el campo político, el aparato judicial, la vida del barrio y la propia complejidad de la burocracia policial". 3

Si bien apareció en experiencias previas, la figura del comisario en la ciudad de México adquirió consistencia a partir de la década de 1870, cuando se crearon oficinas para cada una de las ocho demarcaciones. ${ }^{4}$ Alrededor de éstas se desarrolló de manera paulatina un universo burocratizado (véase el cuadro 1) que, a la luz de reglamentos y presupuestos de egresos, constituiría un verdadero microcosmos. Inicialmente, la planta de empleados se componía del comisario, el escribiente y el mozo de oficios. Recibía instrucciones del inspector de Policía, pero los nombraba el gobierno del Distrito, quien los removía a su antojo. Posteriormente, la planta se amplió para poder cubrir diversas labores y garantizar que se hiciera en dos turnos de 12 horas. Algunas obligaciones de los empleados en las oficinas de las comisarías eran: 1) registrar en un libro el nombre y las generales de los consignados, la causa del arresto, fecha y autoridad que lo remitió, así como el nombre del agente aprehensor y, por último, el resultado del juicio cuando llegaba noticia de éste. 2) Respetar los reglamentos, disuadir riñas, vigilar "sospechosos”, recoger a los ebrios de la vía pública y encerrar a los que cometían escándalos. 3) Elaborar otro libro por cada

2 Kalifa, “L'homme de l'entre-deux”, p. 8.

3 Galeano, "Genealogía del comisario”, p. 14.

4 Rohlfes, "Police”, p. 27. Este autor considera que las comisarías eran “estaciones de policía embrionarias”. 
demarcación anotando las casas y los nombres de los habitantes, registrar incendios, derrumbes, epidemias, tumultos y "sucesos notables". 4) Registrar los establecimientos urbanos, su tipo, números de patente y licencias, horarios, nombre del dueño y calle donde se ubicaba. 5) Llevar un registro de abogados, escribanos, médicos cirujanos, boticarios y parteras "y de todas aquellas personas de cuya profesión pueda necesitar el público". ${ }^{5}$ En el fondo, las comisarías debían generar, ordenar y archivar información sobre una miríada de componentes de la sociedad urbana.

A esa multiplicidad de funciones correspondería una creciente planta de empleados que, sin dejar de ser el sector minoritario dentro de la nómina de policía, representaría de manera bastante clara algunas transformaciones de la administración pública. Es decir, se trató de un sector reducido, pero cualitativamente determinante para concretar los diversos cometidos asignados a la policía. Sobre todo, el agente "de oficina" debe ser examinado toda vez que constituye una mirilla para observar el dinamismo de los empleados públicos, lo cual resulta notorio por el incremento en su número, la especialización de los puestos y la disparidad en su remuneración.

Aunque fueron contempladas en proyectos previos, las comisarías en México adquirieron forma durante el Segundo Imperio y se mantuvieron después del triunfo de la República, pero con una merma en el personal debida al precario estado financiero. Con todo, una vez consolidado el gobierno de Porfirio Díaz,

\footnotetext{
${ }^{5}$ Reglamento para los comisarios, 30 de junio de 1874, en Dublán y Lozano, Legislación, t. XII, pp. 613-616. Otras labores consistían en informar a la inspección general sobre el estado de calles, plazas, jardines, fuentes, monumentos y edificios; cuidar que los niños acudieran a las escuelas públicas; mantener informado al inspector sobre sus cuarteles; notificar sobre el movimiento de huéspedes en hoteles, mesones y hospederías; cuidar de la exactitud de los pesos y medidas, así como trasladarse a los sitios donde ocurriera "algún suceso grave".
} 


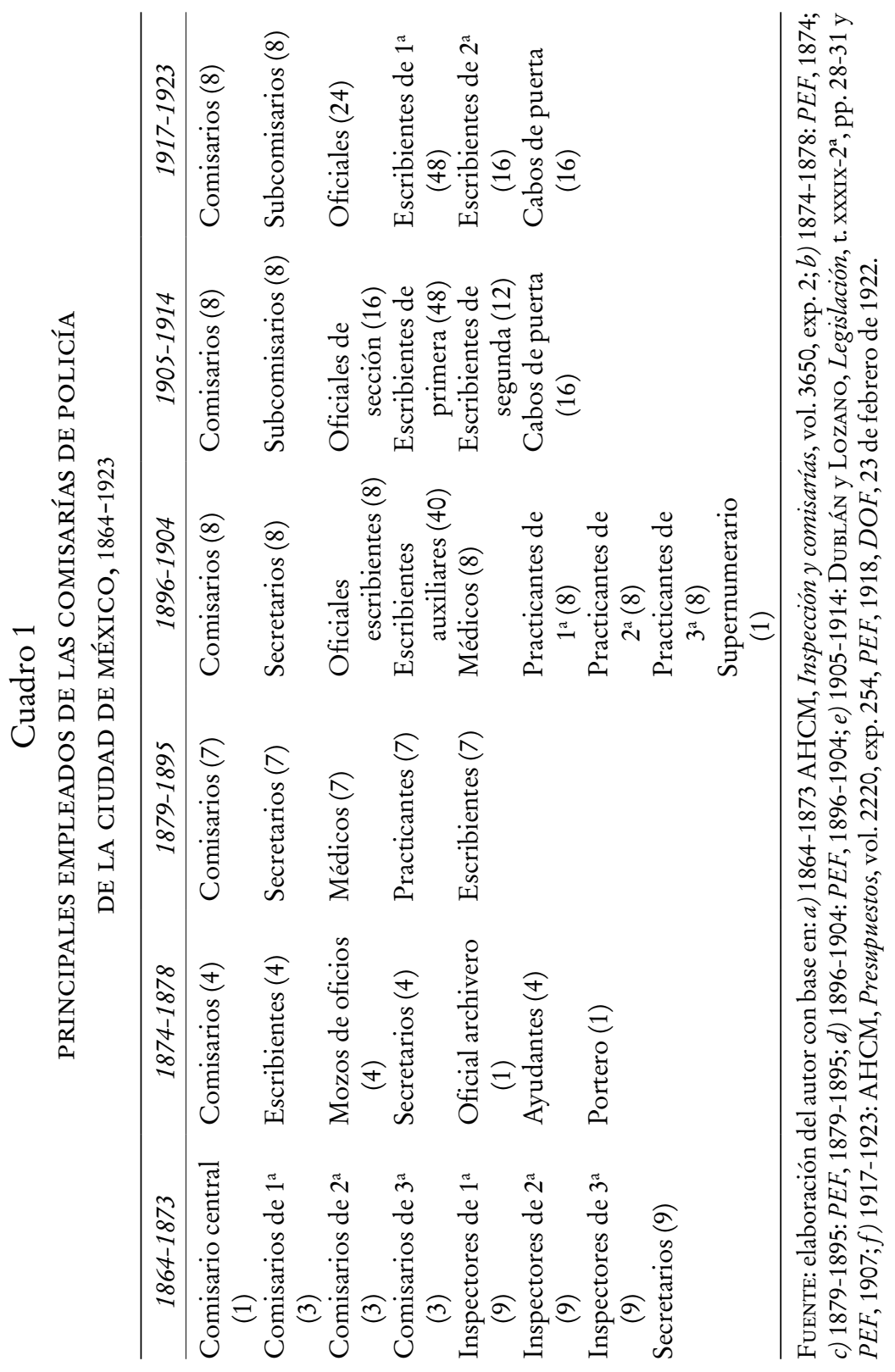


los agentes estrictamente empleados en oficinas de la policía se incrementaron, aproximadamente, de 30 a 100 empleados, cifra que se mantuvo sin demasiados cambios hasta los primeros regímenes posrevolucionarios, cuando se pretendió reafirmar el perfil técnico y militar de los servicios policiales impulsado en el porfiriato. Dado este rasgo continuista, cabe preguntarse si los cargos burocráticos fueron resultado de la conformación del primer Estado mexicano o si eran, de alguna manera, producto del fenómeno que tiempo atrás había sido calificado como "empleomanía”. Refiriéndose a la primera mitad del siglo xIx, José María Luis Mora advirtió la "propensión insaciable del hombre a mandarlo todo y a vivir a costa ajena con el menor trabajo posible". En lugar de disminuir con el incremento de los cargos públicos, dicha tendencia se reforzó al grado de convertir la administración pública en "un campo abierto al favor, a las intrigas y a los más viles manejos", susceptible al "tráfico escandaloso e inmoral entre los dispensadores de las gracias". ${ }^{6}$

A la luz de la documentación, tales apreciaciones son plausibles. Respecto a la reorganización policial se observa, en efecto, cómo el Estado en formación buscó articular la fuerza pública a nivel urbano, rural y militar. En materia de reclutamiento, comportamiento de la burocracia y carreras policiales, se observa lo que Mora diagnosticó en una etapa temprana: en lugar de mitigar la "ambición", el incremento de los empleos públicos generó una expectativa de vida, cuando menos - cabe agregarpara las capas sociales intermedias. Sin desestimar los rasgos "psicológicos" detrás de la "empleomanía”, estudios recientes muestran que las transformaciones en la administración pública ocurridas de 1880 a 1920 dieron un impulso inédito al trabajo en oficinas gubernamentales. Este proceso convocó a una variedad de servidores públicos, así como un complejo proceso de

\footnotetext{
${ }^{6}$ José María Luis Mora, "Discurso sobre los perniciosos efectos de la empleomanía”, El Observador (21 sep. 1827).
} 
especialización y jerarquización por medio de la "instrucción”, pero también mediante la praxis. ${ }^{7}$

Dichos sectores buscaban acomodo como funcionarios de rangos medios, pero incluso los puestos intermedios se componían de una escalera cuyos peldaños salariales comportaban notorias divergencias. Una reducida selección de funcionarios que se desempeñaban en las oficinas de policía, como el comisario, el secretario y el escribano (véase el cuadro 2), revela una diferencia salarial respecto al inspector general, quien ocupaba la punta de la pirámide, pero también en relación con la base de dicha estructura, esto es, con los gendarmes. Para entender la diferenciación de los empleados en el ramo de policía, se advierte cómo la brecha entre el ingreso máximo y el mínimo se elevó sensible y gradualmente durante el último tercio del siglo xix y las primeras décadas del xx. Así, en 1904 los ingresos del inspector eran 8 veces más elevados con respecto al policía de a pie, mientras que llegaría a ser 10 veces más alto en 1910 y 13 veces superior en la década siguiente. Por su parte, el sueldo de los comisarios se multiplicó por seis desde su creación hasta 1920, mientras que los empleados bajo su amparo se incrementaron de 30 a 100.

Está claro, entonces, que el ensanchamiento del Estado resultó en una ampliación de empleados públicos en la capital del país. ${ }^{8}$ Se trata entonces de un proceso generalizado de la administración pública que en otras entidades buscó reemplazar agentes con lealtades locales y grados de autonomía con servidores civiles obedientes y comprometidos con el poder central. Si bien la ciudad de México tenía fuerzas centrípetas en materia de policía que arrebataron al ayuntamiento la policía de seguridad para asignarla al gobernador del Distrito Federal, la dinámica

\footnotetext{
7 Barbosa Cruz, "Empleados públicos”, pp. 129-150.

8 Barbosa Cruz, "Los empleados públicos", pp. 117-154.
} 


\section{Cuadro 2}

SALARIOS MENSUALES DE LOS EMPLEADOS EN LA POLICÍA DE LA CIUDAD DE MÉXICO, 1864-1923

\begin{tabular}{|c|c|c|c|c|c|c|}
\hline Cargo & $\begin{array}{l}1864- \\
1873\end{array}$ & $\begin{array}{l}1874- \\
1878\end{array}$ & $\begin{array}{l}1879- \\
1895\end{array}$ & $\begin{array}{l}1896- \\
1904\end{array}$ & $\begin{array}{l}1905- \\
1914\end{array}$ & $\begin{array}{l}1917- \\
1923\end{array}$ \\
\hline $\begin{array}{l}\text { Inspector } \\
\text { general }\end{array}$ & 200.00 & 300.00 & 300.00 & 375.04 & 501.88 & 790.83 \\
\hline Comisario & 66.67 & 83.33 & 100.00 & 200.14 & 212.92 & 365.00 \\
\hline $\begin{array}{l}\text { Secretario o } \\
\text { subcomisario }\end{array}$ & 50.00 & 50.00 & 50.00 & 150.87 & 152.08 & 273.75 \\
\hline Médico & & 50.00 & 50.00 & - & - & 152.08 \\
\hline Escribiente & - & 50.00 & 50.00 & 51.71 & 60.83 & 76.04 \\
\hline $\begin{array}{l}\text { Guarda/ } \\
\text { gendarme }\end{array}$ & 16.67 & 15.00 & 30.40 & 45.63 & 51.70 & 60.83 \\
\hline
\end{tabular}

FuENTE: véase el cuadro 1.

local en los estados y, sobre todo en los municipios, siguió otros derroteros. ${ }^{9}$

Más allá de este aumento de la policía capitalina, se desconoce una cifra sobre el país en su conjunto. Lo cierto es que del cuerpo policial de la ciudad de México, una fracción sumamente pequeña podría considerarse dentro de los sectores medios por su ingreso, educación, hábitos y condiciones de trabajo. En pocas palabras, los empleados públicos estuvieron lejos de ser asimilados en su totalidad a la incipiente clase media del porfiriato a la posrevolución. ${ }^{10}$ Acaso en las burocracias se puede percibir mayor holgura, pero internamente había un escalafón.

Para caracterizarlos, debe decirse que las miradas de conjunto sobre la sociedad porfiriana sugieren que el incremento de artículos extranjeros para consumo de sectores medios y

\footnotetext{
9 Sánchez García, “Los guardianes de Oaxaca”, pp. 117-148.

10 Pilbeam, The Middle Classes in Europe, pp. 107, 141-142. No existe una relación para el caso mexicano, pero la administración del imperio ruso en 1897 tenía empleados 260000 individuos de los cuales 105000 formaban parte de la policía.
} 
acomodados constituye una prueba de "prosperidad". Sin embargo, las clases medias estaban lejos de vivir holgadamente. El ingreso promedio por familia en estos casos era de 100 pesos mensuales: $25 \%$ se destinaba a la vivienda, $60 \%$ a la comida, $10 \%$ al servicio doméstico y el $5 \%$ restante se gastaba en ropa y otros enseres. ${ }^{11}$ Por su parte, estudios más recientes muestran un notorio encarecimiento de productos alimenticios, como la carne, cuyo caso observa una diferenciación de las calidades y cortes solamente durante el bienio 1883-1884. ${ }^{12}$ Siguiendo a Enriqueta Quiroz, el ingreso mensual de un profesor de instrucción elemental era de 25 pesos al mes; el de un ingeniero de 125 y el de un directivo de la administración pública de 333. En esos años, el comisario ganaba 100 pesos, el secretario 50 -igual que el escribiente - , mientras que el gendarme, 30 . Para la etapa transcurrida de 1917 a 1929, a la insuficiencia de los ingresos de los agentes debe sumarse que "la elevación de los salarios nominales de los trabajadores es consecuencia del proceso inflacionario por el cual atravesó nuestro país", esto es, el crecimiento de los salarios era sumamente relativo. ${ }^{13}$

Por su parte, el censo de 1910 consignó 5262 empleados y funcionarios del gobierno del Distrito Federal, cuando supuestamente $14.3 \%$ de la sociedad urbana se componía de sectores medios. ${ }^{14} \mathrm{El}$ problema es que resulta imposible homologar el binomio empleado público con el de sectores medios, particularmente en lo que atañe al caso de la policía, ya que dentro de ésta prevalecieron variados perfiles socioeconómicos, jerarquías y notorias divergencias salariales. Según la nómina correspondiente al año citado, resulta que casi la mitad de los empleados en el gobierno del Distrito Federal lo estaban en la policía, que

11 González Navarro, El porfiriato. La vida social, p. 390.

12 Quiroz, "Vivir de un salario", p. 120.

13 Gómez Galvarriato y Musacchio, "Un nuevo índice”, p. 55.

14 Orijel Serrano, "Escenas ciudadanas", p. 62. 
sumaba 2635 agentes. De esa cifra, solamente algunos cargos pueden identificarse como intermedios.

La mayoría formaba parte de la base de la pirámide, esto es, pertenecían a una fuerza policial compuesta por gendarmes, un sector con menor remuneración y con un marcado extracto popular, pues en éste figuraban artesanos y jornaleros desempleados que, a falta de sustento, se enrolaban en la policía. A grandes rasgos, estos sujetos eran migrantes de primera generación, promediaban 30 años y los oficios que declaraban tener sugieren su profunda raigambre en el mundo del trabajo artesanal, lo cual no descarta la presencia de un nutrido contingente que había laborado en los peldaños más bajos de los servicios urbanos como barrenderos o porteros, o bien otros que habían prestado temporalmente su fuerza de trabajo en obras públicas. $^{15}$

En cambio, los empleados en las comisarías manifestaron tener una posición social intermedia en razón de sus ingresos, estilos de vida y aspiraciones. Muchas veces desempeñaban labores intercambiables, pero con remuneraciones distintas. En tal sentido, los ocursos en que solicitaban que sus salarios se incrementaran fueron reiterados. En 1883, por ejemplo, se expuso que los sueldos que percibían los empleados de policía se habían mantenido intactos durante décadas. Justificaban sus peticiones de aumento con base en el hecho de que los entonces inspectores desempeñaban funciones meramente de administración urbana. Como el sistema policial "moderno" los obligaba, además, a colaborar con el orden judicial mediante tareas como elaborar las primeras diligencias sobre delitos y faltas, consideraban deseable una compensación económica. Después de negociarlo con el cabildo, los agentes de oficina lograron que se les diera un incremento sustancial, aunque menor al solicitado porque la comisión de Hacienda consideraba demasiado onerosa la

15 Pulido Esteva, “Los gendarmes”, p. 189. 
propuesta inicial. Lo sugerente de estos episodios es que no sólo revelan estrategias para mejorar sus ingresos, sino que hacen patentes inconformidades internas. La disparidad de los sueldos agraviaba a una porción importante de los empleados porque advertían - con bastante malestar - una falta de concordancia entre la carga de trabajo y la retribución económica que recibían. Referidos a este caso, los secretarios de comisaría pidieron homologar sus salarios con respecto a los de los comisarios, alegando la cantidad de asuntos que desahogaban cotidianamente:

Nosotros tomamos con los [comisarios] cada tercer día en el servicio que a aquellos corresponde, teniendo en todo aquel tiempo las mismas responsabilidades y esclavitud que aquellos con mayor trabajo al impuesto porque no dejamos jamás de ejercer las funciones anexas a nuestro empleo de las cuales no nos exoneramos, siendo responsables permanentes del mecanismo y labores de las oficinas. ${ }^{16}$

Además de tener jornadas extenuantes, suplían a los comisarios cuando se ausentaban, por lo cual tenían que "avivar sus imaginaciones" para discernir "negocios penosos y desagradables". Reducido a tiempo de trabajo, los comisarios permanecían 24 horas seguidas cada tercer día. El resto de la semana solamente gozaban de cuatro o cinco horas de descanso, por lo cual consideraban de "equidad y justicia" que se incrementara su sueldo y, sobre todo, que fuera similar al que percibían los comisarios.

En otras ocasiones, la solución para despresurizar estas demandas tendió menos a incrementar los sueldos que a promover el ascenso de secretario a comisario. Curiosamente, el resto de los empleados - como los escribientes, el personal de

16 AHCM, fondo Ayuntamiento de México, sección Policía, Inspección General y Comisarías, vol. 3653, exp. 284, Moción de varios regidores consultando aumento de sueldo a los inspectores de policía y secretario, ff. 5 y 6, México D. F., 5 de enero de 1884. 
identificación y los practicantes - casi no participaron en estas demandas. A pesar de inconformarse, aceptaron el desigual incremento de salarios, es decir, fueron menos persistentes en expresar las penurias que enfrentaban para sostener a sus familias.

Ahora bien, debe destacarse que los salarios no siempre fueron el señuelo para ocupar un cargo en los servicios policiales. ${ }^{17}$ Muchos de los agentes se enrolaron debido a una combinación de elementos. En primer lugar, es cierto que se trataba de un ingreso reducido pero, a diferencia de otros trabajos, era bastante estable. En segundo, tenían una serie de beneficios que figuraban en los reglamentos a pesar de que fueron inciertos al llevarse a cabo. Entre otros destacaban las licencias con o sin goce de sueldo, la posibilidad de pensionarse por años de servicio o incapacidad, y algunos gastos, como los de entierro, estaban previstos. Por último, los empleados que desempeñaban labores de escritorio ostentaban un orgullo independiente de la retribución económica de su trabajo, pues a diferencia de la tosquedad del patrullaje y vigilancia ejercidos por los gendarmes, los agentes de oficina ejecutaban actividades que requerían "instrucción”. Sin embargo, cabe preguntarse si éstos manifestaron alguna identidad de clase $y$, en particular, si se pensaron como parte de las pequeñas burguesías urbanas en su esfuerzo por ser reconocidos como empleados públicos.

En razón de la diversa composición social observable dentro de las oficinas públicas, debe tomarse con recelo la categoría "clase media". ${ }^{18}$ Con matices, los sistemas de diferenciación

17 Emsley, “The Policeman as Worker”, p. 100.

18 Sobre el uso historiográfico de la categoría "clase media”, véase ADAmovsky, “'Clase media”, pp. 115-138. Este autor repara en la insuficiencia metodológica de extrapolar históricamente variables ocupacionales y niveles de ingreso que se emplean en la contemporaneidad por las ciencias sociales; observa los límites de las propuestas formuladas por Michael Mann y Jürgen Kocka y, por último, repasa los equívocos para traducir temporal y nacionalmente el 
social finiseculares definieron a las clases medias con base en una mezcla de condiciones objetivas y simbólicas. Entre las primeras figuraban desempeñar ocupaciones no manuales, percibir un salario moderado pero estable y gozar de mayor instrucción. Entre las segundas estaban demostrar mediante sociabilidades, hábitos de consumo y representaciones impresas un repertorio de estilos de vida que los separaba de los sectores populares, así como explicitar aspiraciones de estabilidad cuando no de ascenso social. Una crónica sobre los parroquianos del Café Colón sugería que las clases medias se componían "de los inclasificados que no visten chaqueta pero que no saben llevar bien puesta la levita”. Según este testimonio, se trataba de un sector formado por "propietarios modestos, profesionistas y funcionarios". ${ }^{19}$ Siguiendo a Ezequiel Adamovsky, es posible considerar que esa imagen hacía eco de una concepción "residual” del binomio clase media. Lo cierto es que era una representación bastante socorrida cuando se retrataba a los empleados como aquellos

concepto de clase media. Para caracterizar socialmente a los funcionarios de las comisarías, considero sugerente la perspectiva de este autor para conceptualizar la clase media con base en "la experiencia de grupos sociales concretos en situaciones históricas delimitadas", así como con "las construcciones discursivas que los convocan a la unidad (p. 135).

19 “La clase media en el Café Colón”, El Mundo Ilustrado (31 jul. 1898). Está claro que entonces se referían a clase media como algo distinto al burgués, término entonces reservado al potentado empresarial o financiero que pertenecía a las élites. Dichas representaciones no siempre eran encomiásticas. Por ejemplo, de los jóvenes empleados en oficinas públicas se decía: “es el señorito el empleado inepto y pretencioso, que pasa en tertulia las horas de oficina, para luego terminar su trabajoso día en la cantina o en compañía de sílfides averiadas; es señorito el mozalbete ridículo que sin rentas ni oficio, ni profesión alguna, pero hablante de todo y de todos con sentenciosa prosopopeya, es constante y entusiasta adorador de la tanda pornográfica, asiduo concurrente al café, a la cantina, a las francachelas y se exhibe en las avenidas más concurridas de la capital": "Obreros y señoritos", La Clase Media: Semanario de politica, literatura, comercio, agricultura, avisos y de propaganda contra los vicios que degradan al hombre (10 jul. 1908). 
que laboraban en las comisarías y que, definitivamente, buscaron diferenciarse de los gendarmes.

Otras prácticas que conferían rasgos identitarios estaban relacionadas con asociarse. El problema es que muchas veces esto tendía a refrendar más la pertenencia a la corporación policial que a expresar vínculos de clase. Si bien tenían prohibido sindicalizarse, los empleados de policía podían formar sociedades de amigos, de apoyo mutuo, así como disponer de préstamos y gratificaciones obtenidos de una caja de ahorros. ${ }^{20}$ Supuestamente, ésta debía solventar licencias, gastos funerarios y, si bien no hay noticias de que se hayan otorgado, era una fórmula que daba liquidez a la institución para proporcionar pensiones a quienes se retiraban. Hacia el periodo revolucionario, se fundaron espacios de sociabilidad tendientes a refrendar el "espíritu de cuerpo". Dentro de éstos se encontraba el casino de policía, equipos de béisbol y futbol, así como la celebración de rituales dentro de los cuales destacaba el "día de la policía". Acaso entonces pudiera pensarse que la burocracia de las comisarías admitía su pertenencia a la corporación policial.

Más allá de las asociaciones, pertenecer a la policía permitía acceder a otros empleos en la administración pública. Esto parecía estar vinculado más a la burocracia policial, precisamente el sector que enalteció su supuesto carácter técnico y, al mismo tiempo, pergeñó una imagen oprobiosa del gendarme como una ocupación vil debido a su presunta inmoralidad, indisciplina y rusticidad. En contraste con los llamados "tecolotes" o "cuicos", el personal de oficina mantuvo relativamente activo un discurso que aseguraba el acceso a una posición social respetable, en concomitancia con el carácter de intermediarios atribuido a los empleados públicos. En suma, un sueldo fijo, licencias, pensiones, beneficios, la movilidad escalafonaria y - en menor medida - social eran aspectos relevantes en las actitudes de los

20 EmsLey, "The Policeman as Worker”, pp. 97-98. 
agentes de oficina frente a su trabajo. Para los empleados públicos de las comisarías existía mayor itinerancia en oficinas tanto de la policía como de los tribunales u otras dependencias. El problema de la identidad social, en esencia, no era reducible al ingreso sino a las propias características del trabajo técnico, como si éste ennobleciera y cualificara a los agentes. Por ejemplo, un escribano en 1910 ganaba al mes tan sólo nueve pesos más que los gendarmes y, dadas sus competencias en lectoescritura, entre otras capacidades, se diferenciaba de los sectores populares. ${ }^{21} \mathrm{~A}$ pesar de esto, esos funcionarios de oficina constituían un universo social tan plural como irreductible a una categoría unitaria.

\section{LOS EMPLEADOS DE LAS COMISARÍAS}

Es complicado reconstruir un perfil acabado de los empleados en las comisarías porque la visibilidad de esos sujetos a partir de las fuentes suele limitarse a los cargos directivos. En términos generales, se trataba de individuos reclutados por recomendación del inspector general o los comisarios, quienes pusieron creciente atención, por un lado, en profesionistas que trabajaron en dependencias públicas dentro o fuera del ámbito policial. Entre las formas de acceder a los puestos, se encontraban escribientes que en ocasiones lograban ascender hasta convertirse en secretarios. Por el otro, es observable el enrolamiento a partir de redes de parentesco o influencias de algún potentado. Si la primera ruta apuntaba en cierta medida a la meritocracia; la segunda, en cambio, sugiere que hubo casos de nepotismo. Sin descartarla de manera abrupta, la tercera vía, que consistía en reclutar entre supuestos bandidos a la policía, parece

${ }^{21}$ Como sugiere Adamovsky recuperando a Gino Germani, "la frontera entre clase obrera y clase media pasaba por la naturaleza manual/no manual del trabajo”. Adamovsky, “'Clase media”, p. 117. 
relativamente ajena al mundo de la comisaría y mucho más afín tanto al cuerpo de Rurales como a la policía reservada o encubierta. ${ }^{22}$ Por lo tanto, señalaré tan sólo la incorporación según los méritos, la recomendación, o bien aquellos nombramientos que resultaron de una mezcla de ambas.

Esa hibridación de formas, estilos y culturas en la conformación de la administración pública ha sido bastante señalada por la historiografía reciente sobre el porfiriato y el régimen posrevolucionario. Así, se observan trayectorias policiales de técnicos que ascendieron, como Indalecio Gómez Llata, quien de escribiente llegaría a ser secretario y luego comisario. Debido a sus "reconocidas" aptitudes rotó en varios cargos para suplir, cubrir interinatos y desempeñar comisiones especiales. Figuró como empleado en el gobierno del Distrito Federal por vez primera en calidad de escribiente en 1878. Hacia el segundo periodo presidencial de Díaz, fue secretario de la $4^{a}$ demarcación de policía, y en 1892 desempeñaba el mismo cargo, pero en la $2^{a}$ comisaría. Además de aparecer de manera reiterada, resulta de interés este personaje por la cantidad y duración de las licencias con goce de sueldo que se le concedieron, así como por el hecho de que su movilidad dentro del ramo no siempre fue vertical. En una ocasión se le concedieron cinco meses consecutivos percibiendo su salario mientras se recuperaba de una enfermedad y, tal vez por ello, se reincorporó como escribiente en lugar de secretario. ${ }^{23}$ En el Diccionario de policía que escribió, se refirió a sí mismo como "empleado superior del ramo". De ese modo,

22 Para el caso de la policía rural véase VANDERwood, Desorden y progreso, pp. 78-87. Sobre el reclutamiento de exintegrantes de la banda del Tigre de Santa Julia en la policía reservada: AHCM, Ayuntamiento de México, Inspección General de Policía, Informes y Correspondencia, c. 1, exp. 7, f. 3. Memorándum para el C. Gobernador, México D.F., 29 de marzo de 1922.

23 AHCM, Ayuntamiento de México, Policía, Inspección General y Comisarías, vol. 3654, exp. 456, f.1; vol. 3656, exp. 649, f. 1, exp. 733, f. 1, exp. 755, f. 1 y exp. 769, f. 1. Asimismo, véase "Cambio de secretario", Diario del Hogar (19 jun. 1892). 
Gómez Llata muestra a cabalidad un proceso de autoidentificación amparado, según decía, en 20 años de servicios dentro de las oficinas de policía. Ese hecho le permitió, posteriormente, ser titular de la séptima y luego de la primera comisaría, en razón de considerársele un "ilustrado y antiguo empleado de policía”. ${ }^{24}$ Este caso representa, entonces, el lenguaje del mérito, la probidad y la experiencia para justificar la larga trayectoria de este funcionario, quien a la sazón recibió toda la confianza del gobierno del Distrito Federal. Si bien con menos años de servicio, el periodista y criminólogo Carlos Roumagnac también destacó como empleado en comisarías, ${ }^{25}$ siendo un caso similar el de Benjamín A. Martínez, quien durante el periodo posrevolucionario sería reconocido por impulsar métodos de identificación dactiloscópica. Tanto Roumagnac como Martínez fueron piezas clave en la Escuela Técnica de Policía (1923), instancia llamada a profesionalizar a los empleados de este ramo, en particular a quienes se ocupaban de labores sustanciales en las oficinas y sus secciones médicas. De ese modo, este perfil alternó o complementó el ejercicio práctico en las comisarías con la escritura sobre temas policiales y delincuenciales. A propósito de esto, Diego Galeano ha advertido el protagonismo de los comisarios bonaerenses en el desarrollo de la cultura policial escrita, destacadamente en las revistas, manuales y relatos en primera persona. ${ }^{26}$ Esto comporta una notoria similitud con el caso mexicano, en el cual los empleados en comisarías solían leer y escribir, encontrándose entre ellos los primeros editores

${ }^{24}$ Gómez Llata, Diccionario de policía, p. 6. Dicha obra tuvo una edición en 1894 y diez años más tarde, se publicó la segunda. Véase también "Movimiento de empleados", Gaceta de Policía: Semanario Ilustrado (29 oct. 1905), así como "Directorio de policía", Boletín de Policía: Semanario Ilustrado (12 sep. 1909).

25 "Los últimos nombramientos ante el Sr. Ministro de Gobernación”, $L a$ Libertad (28 jun. 1903).

${ }^{26}$ Galeano, "Genealogía del comisario", p. 17. 
de semanarios y libros especializados en policía. Nada extraño resulta que la posibilidad de participar en esos circuitos del saber policial fuera subrayado en los informes del inspector de comisarías. En éstos se manifestaba el aprecio de empleados con "conocimientos de la ciencia jurídica", o bien cuando se trataba de un estudiante de jurisprudencia que ostentaba "la ilustración necesaria" ${ }^{27}$ Dichas valoraciones también estimaban al personal que se mostraba empeñoso y honorable. La dedicación y el honor, consecuentemente, equilibraban la balanza para calificar el desempeño de individuos con "pocos conocimientos en el ramo de policía”. ${ }^{28}$ De manera paradójica, entre las principales críticas al personal de estas oficinas se encontraba, precisamente, su escasa instrucción:

La mayoría de los que han ocupado los puestos de comisarios han sido de la gleba ignara de los favorecidos, e individuos que desconocen en lo absoluto los más rudimentarios principios del derecho usual y, por qué no decirlo, carecen de un criterio medianamente deductivo, que les impide dirigir el curso de cualquier averiguación, por sencilla que esta sea; y lo que decimos de los comisarios con mucha mayor razón se puede asentar de los empleados de segunda categoría que pululan en aquellas agencias. ${ }^{29}$

Si bien el escalafón meritocrático era una de las vías para desenvolverse en una suerte de cursus honorum policial, había otras rutas para acceder, mantenerse y promoverse en la función pública. En tal sentido, es notoria la importancia de las redes de parentesco y la recomendación de algún potentado. Aquí se

27 AHCM, Ayuntamiento de México, Justicia Comisarias, vol. 2717, exp. 1, f. 8. Hoja de conceptos del personal, México D.F., 16 de julio de 1919.

${ }_{28}$ AHCM, Ayuntamiento de México, Justicia Comisarías, vol. 2717, exp. 2, f. 1. Informe de la visita de inspección general practicada a la $2^{a}$ comisaría, México D.F., 8 de agosto de 1919.

29 "Las comisarías", Redención (8 jun. 1917). 
inscribe el caso, por ejemplo, de Octaviano Liceaga, hermano de Eduardo, quien se encumbraría como emblema del gremio médico, que fue participativo en camarillas políticas y titular del Consejo Superior de Salubridad. ${ }^{30}$ En 1884 Octaviano Liceaga era jefe de la sección segunda de la Secretaría de Gobierno, quedando igualmente a cargo de la policía civil. En ese mismo año fue "agente especial” de la comisión de agricultura presidida por Gustavo Ruiz y Sandoval y conformada, entre otros, por Antonio Rivas Mercado. ${ }^{31}$ Es decir, vemos un itinerario completamente ajeno a la policía, quizá para evitar complicidades que resultaban de hacer carrera dentro de las comisarías. El de Liceaga ofrecía un perfil idóneo por su relativa distancia respecto a los servicios de policía, que se consideraban sensibles al tráfico de influencias y expuestos a la corrupción. En 1899 se desempeñó al frente de la quinta comisaría, donde trabajaban, como escribano, Jesús M. Rábago - autor de la crónica Historia del gran crimen-, así como en el servicio médico Salvador de Quevedo y Zubieta - autor de la novela La camada-, escritos que se ocuparon del supuesto atentado contra Porfirio Díaz que derivó en el escándalo policial de mayor impacto en la opinión pública finisecular. ${ }^{32}$ Lo cierto es que Liceaga tuvo una rotación de cargos dentro y fuera de las comisarías, al ser varias veces titular de las primera, tercera y sexta de 1889 a $1900 .{ }^{33}$ Su probidad para el servicio no fue destacada, mientras que su movilidad hacia otros sectores de la administración pública sugiere que, a

\footnotetext{
30 Agostoni, Monuments of Progress, pp. 144-147.

31 “Noticias de la ciudad”, El Tiempo (9 ago. 1884); “Agricultura”, El Diario del Hogar (2 jul. 1884).

32 Sobre el atentado y el escándalo policial, pueden verse tanto crónicas de la época como estudios monográficos: RábAGO, Historia del gran crimen; BARrera Bassols, El caso Villavicencio y, más recientemente, Lomnitz, El primer linchamiento.

33 AHCM, Ayuntamiento de México, Policía, Inspección General y Comisarías, vol. 3654, exp. 493, ff. 1-5; vol. 3655, exp. 546, ff. y 585, ff. 1-4, ff. 1-16; vol. 3656, exp. 779, ff. 1-4.
} 
diferencia de Gómez Llata, tenía poca o nula identidad con los cuerpos policiales.

Finalmente, otro caso donde las redes de parentesco desempeñaron un papel fundamental fue el del inspector general Ignacio Ugalde, pues sin su mediación difícilmente hubieran sido contratados otros cuatro parientes que, incluso después de su fallecimiento, permanecieron rotando de escribientes, ayudantes y oficiales en prácticamente las ocho comisarías. ${ }^{34}$ Salvo uno de ellos que se desempeñó durante décadas como escribiente - y que hizo un uso desmesurado de las licencias con goce de sueldo-, el resto manifiesta rasgos difusos en cuanto al mérito. Lograron obtener la pensión tras la muerte del benefactor que les había dado empleo. De hecho, las exequias fúnebres revelan la conveniencia de demostrar lealtades, pues la mayor parte de los empleados de policía participó en el cortejo para honrar al difunto inspector general. ${ }^{35}$

De otros perfiles es posible constatar que se trató de individuos empleados de manera intermitente cuando no inestable, promediaban cuarenta años, eran casados y se identificaban a sí mismos como empleados públicos. Obtener un sueldo que oscilaba anualmente de 500 a 1200 pesos en 1910 era, sin duda, uno de los mayores alicientes para encontrar un cargo dentro de la policía. Sin embargo, fue un empleo que enfrentó incertidumbres durante el colapso del régimen porfiriano. En efecto, la vulnerabilidad se agravó durante la fase armada de la Revolución. Salvo en 1915, los presupuestos asignados a la seguridad pública

34 AHCM, Ayuntamiento de México, Policía, Inspección General y Comisarías, vol. 3653, exp. 208, f. 9, exp. 213, f. 5, exp. 219, f. 2; exp. 276; vol. 3654, exp. 520, ff. 1-4, exp. 524, f. 1, exp. 230, f. 1; vol. 3655, exp. 549, ff. 1-8. Véase, además "Inspecciones de policía”, El Municipio Libre (24 ene. 1884).

35 AHCM, Ayuntamiento de México, Policía, Inspección General y Comisarias, vol. 3653, exp. 276, ff. 1-3 y "Funerales", El Nacional (15 mayo 1883). La crónica del funeral detalló que "la caja fúnebre fue elegantísima, con muchos adornos de plata. Seguían ocho vagones a la mejor carroza que tiene la empresa de ferrocarriles del Distrito". 
de la municipalidad de México indican continuidades en el organigrama de la policía, pero esto contrasta con otros registros que evidencian cómo el statu quo se vio comprometido por efectos de la guerra. ${ }^{36} \mathrm{Si}$ bien los funcionarios aseguraban que los servicios policiales eran ajenos a las "orientaciones políticas" de cada facción, la realidad fue otra. ${ }^{37} \mathrm{~A}$ esto se suman los efectos materiales de la lucha armada, como señala un reclamo de indemnización del comisario de la 6 a demarcación durante la Decena Trágica. Su testimonio ofrece una idea de las condiciones materiales en las cuales vivían estos funcionarios, condiciones que, desde luego, buscaron mantener a toda costa. En el mencionado documento exigía que se pagaran 1000 pesos por los perjuicios ocasionados a los enseres dispuestos en el edificio de la comisaría, donde una granada devastó el departamento destinado al costurero y las habitaciones que ocupaba el comisario. El acta de este incidente permite ver que buena parte del mobiliario era propiedad de los comisarios: una máquina de coser Singer nueva, un ropero de dos lunas, dos burós de encino, un tocador con luna francesa hecho de roble, cortinas, etc. Como consideró amenazada la seguridad de su familia, abandonó el edificio para encontrar a su regreso que faltaban 68.50 pesos producto de las multas y 500 pesos en billetes de banco, que eran parte "de sus ahorros". ${ }^{38}$ Tanto por el lujo de los muebles como por el hecho de tener dinero ahorrado, debe identificarse a este individuo en

36 AHCM, Ayuntamiento de México, Hacienda Presupuestos, vol. 2220, exp. 200, f. 18, Presupuesto general de la municipalidad de México para el año de 1915. Dictamen de la comisión de Hacienda. Sobre la ciudad de México durante la Revolución, véase Rodríguez Kuri, Historia del desasosiego, pp. 141-178.

37 Davis, "Historia de detectives", pp. 69-94.

38 AHCM, Ayuntamiento de México, Gobernación, Comisaria de Policía, c. 1, exp. 3 , f. 4. Aureliano Herrera solicita indemnización por los perjuicios que sufrió, 28 de junio de 1913. Pudiera pensarse que la versión rendida por este comisario fue una coartada para hacerse del dinero recaudado por concepto de multas, pero las averiguaciones practicadas no exploraron dicha posibilidad. 
la parte más alta de los sectores medios que podrían encontrarse empleados en las comisarías.

Ahora bien, si las redes de parentesco y poder se impusieron en los cargos altos de las comisarías, el acceso a los empleos subalternos como los de escribano, archivista, telegrafista, telefonista, camillero, enfermero y una miríada de oficios técnicos, estuvieron estrechamente ligados a la recomendación del comisario o del inspector general y, ocasionalmente, también intervenían y movían su influencia altos funcionarios, como secretarios de Estado. Con la recomendación favorable de José Y. Limantour, Ana Ortiz Monasterio obtuvo el empleo de enfermera y el joven doctor Jesús Sola el de médico de comisarías. ${ }^{39}$ Estas prácticas para conformar las plantas de empleados no eran exclusivas de la policía, es decir, estaban respaldadas en una manera de concebir el acceso a los cargos públicos que encalló en el habitus político mexicano, generando marcadas líneas de continuidad entre regímenes. Incluso, la recomendación anulaba señalamientos por falta de probidad, como un escribano que obtuvo el empleo a pesar de señalarse que era "incompetente" y que "escribía mal y sin ortografía". 40

Así, la inestabilidad provocada por el ingreso de tropas revolucionarias que alternaron su dominio en la capital no modificó tan drásticamente las formas de reclutar personal policiaco, pero sí se observa una reconfiguración según la facción que estableció su mando. Las peticiones abiertamente oportunistas para obtener un cargo, así como las referidas a compensar salarios

39 AHCM, Ayuntamiento de México, Policía, Inspección General y Comisarías, vol. 3653, exp. 208, ff. 2-23. Nombramiento interino de escribientes en las ocho comisarías, 30 de enero de 1881. CEHM-CARSO, fondo José Y. Limantour, sección $2^{\mathrm{a}}$, c. 13, leg. 2, exp. 13, ff. 1-8. Correspondencia entre José Y. Limantour y Ramón Corral en relación con la recomendación a favor de Ana Ortiz Monasterio y Jesús Sola, México D.F., 3 de enero a 1º de julio de 1908.

40 AHCM, Ayuntamiento de México, Justicia Comisarías, vol. 2717, exp. 5, f. 12. Informe de la visita de inspección general practicada a la $5^{\text {a }}$ comisaría, México D.F., 16 de julio de 1919. 
vencidos, apelaban al hecho de haber colaborado con determinado grupo. Es probable que el favor se pidiera de boca en boca, pero algunas solicitudes de esta naturaleza se expresaron través de cartas que discurrían entre la especulación y la deferencia:

[T]uve que radicarme en la ciudad de México por tener alguna familia que me presta su ayuda, pero estando próxima la entrada del Glorioso Ejército Constitucionalista que usted dignamente representa a la excapital, desearía ser uno de los primeros empleados que usted mandará ocupando el puesto de oficial $2^{\circ}$ en la subdirección de ramos municipales o en alguna de las comisarías, puestos que ya conozco o en un lugar donde juzgue conveniente y le pueda ser útil. ${ }^{41}$

El desenlace previsto por el autor de la carta citada fue certero. A partir de entonces, esas expresiones fueron todavía más notorias cuando los constitucionalistas resultaron victoriosos. En una carta dirigida a Venustiano Carranza, un exempleado de la Secretaría de Hacienda solicitó el cargo de comisario en razón de estar vacante, apelando a su "calidad de revolucionario y ciudadano mexicano" y a que en otras ocasiones había recibido la confianza del jefe del Ejército Constitucionalista, a quien alabó por su supuesto apego a la "bondad y la justicia". ${ }^{2}$ Evidentemente, la sociedad urbana había padecido escasez, desempleo y ese tipo de peticiones se reiteraron, sobre todo para quienes colaboraron con los triunfadores, a quienes pedían recomendaciones o colocaciones como si se tratase de un favor o dádiva. Por "encontrarse sin acomodo", un exoficial de policía que

${ }^{41}$ CEHM-CARSO, Manuscritos del Primer Jefe del Ejército Constitucionalista, sección 43, c. 1, exp. 43, 1 f. Carta manuscrita de Gabriel Torres a Venustiano Carranza, Puebla, 28 de junio de 1915.

${ }^{42}$ CEHM-CARSO, Manuscritos del Primer Jefe del Ejército Constitucionalista, sección 126, c. 1, exp. 126, f. 2. Carta de José Flores García a Venustiano Carranza, México D.F., 5 de febrero de 1918. 
había trabajado en la $8^{a}$ comisaría solicitaba empleo o, cuando menos, que se le restituyese el dinero que se le debía..$^{43}$ Igual que bajo el régimen porfiriano, sin dejar de mostrar los méritos y adhesión, se buscaba interlocución con el Ejecutivo como si este fuese un patriarca para resarcir la penuria y el desempleo, como muestra el fragmento de la siguiente misiva: "Por circunstancias económicas, desearía pasar con el mismo carácter a la $1^{\mathrm{a}} \mathrm{o}$ a la $3^{\mathrm{a}}$ demarcación, por cuyo motivo respetuosamente suplico a ud. se sirva concederme esta gracia, con lo que seré infinitamente favorecido". ${ }^{44}$

Como se advierte, las consecuencias de la Revolución exhiben, por un lado, que la inestabilidad afectó decisivamente a los empleados públicos. Por el otro, los efectos de la lucha armada comportaron un reacomodo de fuerzas que abrió la oportunidad a individuos cercanos a la facción constitucionalista. En ese sentido, el lenguaje de las cartas para conseguir un trabajo en la policía de la ciudad de México se acercó a las formalidades propias de la petición de una gracia más que a la solicitud de un empleo. Primero con la victoria de Carranza, y con mayor claridad una vez que los sonorenses se impusieron al concluir la rebelión de Agua Prieta, el personal policial volvería a nombrarse de arriba hacia abajo con la venia del presidente.

La conformación de los cuerpos policiales durante la década de 1920 subrayó cada vez más el carácter militar. Esto obedecía, probablemente, al reclutamiento de excombatientes a quienes no se les reconoció el grado. De manera paralela, se reactivó el

${ }^{43}$ CEHM-CARSO, Manuscritos del Primer Jefe del Ejército Constitucionalista, sección 143, c. 1, exp. 143, f. 1. Carta de Vicente Covarrubias a Venustiano Carranza, México D.F., 24 de diciembre de 1919. Aseguraba que se le debían 510 pesos en oro, correspondientes a $25 \%$ de su sueldo por haber trabajado seis meses en la comisaría.

${ }^{44}$ CEHM-CARSO, Manuscritos del Primer Jefe del Ejército Constitucionalista, sección 136, c. 1, legajo 15517, exp. 136, f. 1. Carta de Manuel Sánchez a Venustiano Carranza, México D.F., 1o de julio de 1919. 
anhelo de "profesionalizar" a los empleados en las comisarías por medio de la Escuela Técnica de Policía (ETP), donde se impartieron cursos de policía administrativa, fotografía, identificación, peritaje, investigación policial y taquimecanografía para aspirantes a las carreras de "gendarme técnico, para comisarios y oficiales terceros, para empleados subalternos de comisarías [y] para agentes de las comisiones de seguridad". ${ }^{45}$ Para ello, se tomaron en cuenta programas "aceptados en las ciudades más importantes del mundo" con escuelas análogas ya establecidas, principalmente los de la Academia de Policía de Nueva York, formulados por el exinspector de esa ciudad, Richard E. Enright. Después de ocho meses de funcionamiento, la ETP tenía alrededor de 400 inscritos y se aplicaron más de un centenar de exámenes.

Los resultados de esta nueva modalidad de reclutamiento/ regularización del personal policial parecen bastante ambiguos a la luz de informes practicados en la década de 1930. Sin embargo, la sola presencia de la ETP supone un corte temporal toda vez que antes de su fundación los agentes se formaban empíricamente. Aquellos cargos que exigían instrucción dentro de las comisarías se obtuvieron mediante redes de parentesco, recomendación y méritos. Los pocos que tuvieron educación formal, la realizaron en las escuelas de jurisprudencia o medicina en el caso de profesiones liberales. Por su parte, es probable que el personal que desempeñaba trabajos técnicos (mecanógrafos, archivistas o personal más técnico) se haya formado en la Escuela Superior de Comercio.

Ahora bien, los casos desarrollados en este apartado sugieren la importancia en la rotación de cargos. Para explicar esa

45 AHCM, Gobierno del Distrito Federal, Gobernación, Comisaría de Policía, c. 2, exp. 139, f. 28. Informe de las labores desarrolladas por la Inspección General de Policía y sus dependencias, correspondientes al periodo del 1을 septiembre de 1925 al 15 de julio de 1926, México D.F., 3 de agosto de 1926. Sobre los cursos, véase "La labor de la Escuela Científica de Policía durante los últimos tres meses", Revista de policía (30 feb. 1926). 
movilidad, se advierte que los individuos que desarrollaron una trayectoria en la policía se ganaron la confianza de los altos mandos. Así, cada vez que un puesto quedaba disponible por licencia, cese o defunción, dichos individuos eran llamados para suplir las vacantes por medio de enroques. Finalmente, con base en los informes del inspector puede constatarse la presencia de un cada vez más nutrido número de escribientes, taquígrafos, telegrafistas y telefonistas, quienes conformaban una planta con menor remuneración y que laboraban jornadas de 12 horas. Tal transformación de la planta de empleados rara vez fue acompañada de espacios de trabajo apropiados. Como se verá a continuación, muchas veces el personal se encontraba hacinado en oficinas inadecuadas para satisfacer las exigencias de la policía calificada como técnica o científica.

\section{LAS OFICINAS POLICIALES: \\ ¿UN ESPACIO PARA LA BUROCRACIA?}

Para evitar reproducir una imagen imprecisa de la burocracia policial, sus condiciones de trabajo y labores rutinarias, es necesario conocer algunas características físicas de las comisarías. El análisis prestado a los espacios laborales ha sido un factor sumamente presente para entender el mundo del artesanado y de los trabajos fabriles, pero sumamente desatendido en la exploración histórica de los empleados públicos. Es cierto que las rutinas de trabajo dentro de las comisarías se transformaron en la medida en que fueron engranes de la administración municipal, en la retención de detenidos por presuntas faltas así como en la administración de justicia por practicarse allí las primeras averiguaciones sobre supuestos delitos. ${ }^{46}$ En razón de

\footnotetext{
${ }_{46}$ De hecho, en 1903 los comisarios “foráneos” debían practicar las primeras diligencias donde no hubiera juzgados de paz. Véase Gómez Llata, Diccionario de policía, p. 31.
} 
esto, se poblaron de un personal cada vez más nutrido y, desde luego, especializado mas no necesariamente disciplinado. El número de escribientes se multiplicó de 8 a 64 entre 1874 y 1920; aparecieron, en la medida en que se tecnificaron algunas labores, archivistas, pagadores, fotógrafos, telegrafistas y telefonistas, choferes, así como profesionistas, en particular abogados y médicos. Sin embargo, cabe preguntarse si los espacios correspondieron a estas transformaciones en la concepción del poder policial.

En general, las comisarías se ubicaron en edificios rentados a particulares. Salvo el despacho del inspector, localizado en una recámara del Palacio de la Diputación, el resto de las oficinas de policía se desperdigaron en casas o habitaciones con características bastante disímbolas. Solamente se exigía que estuvieran “en un lugar céntrico” según la demarcación. Si bien los comisarios eran responsables de elegir el edificio, firmaba el contrato el presidente del ayuntamiento. En sus cláusulas, ese documento responsabilizaba al propietario por los gastos de mantenimiento, toda vez que el deterioro fuese consecuencia de su uso corriente. Si éste dejaba de hacerlo, la Dirección de Obras Públicas se encargaba de las modificaciones necesarias a cuenta de la renta. Esto a menudo suscitó conflictos con los propietarios. Por ejemplo, cuando se entregó el edificio de la $2^{\text {a }}$ comisaría, ubicada en la plaza de Tecpan de San Juan, el dueño exigió la reparación del inmueble, pues aseguró que se le entregó “en estado de destrucción completo [...] no siendo por el uso natural" ${ }^{47}$ Sin entrar en pormenores del caso, se sobreentiende que este tipo de incidentes alejaban a los agentes de la ejecución de sus labores, pues era materialmente imposible que operaran con eficacia los despachos de identificación y, sobre todo,

47 AHCM, Ayuntamiento de México, Policía, Inspección General y Comisarías, vol. 3652, exp. 146, f. 1. Manuel Zapiain pide indemnización..., México D. F., 10 de junio de 1878. 
exhibían el descuido de los comisarios y el personal con las casas que rentaban. Lo cierto es que las características de las comisarías eran sumamente variadas. Un ejemplo temprano de estos edificios sugiere que eran edificaciones de una o dos plantas, pero las condiciones cambiaban según el nivel de urbanización de cada rumbo de la ciudad. ${ }^{48}$

El hecho de que se arrendaran a particulares puso a las comisarías en una vulnerabilidad evidente. Los arrendadores se inconformaban por el uso, a veces cambiaban de propietarios por juicios sucesorios o simplemente impugnaban los contratos después de haberlos firmado. A la necesidad de evitar estas contingencias se sumó el anhelo de modernizar los servicios policiales, motivo por el cual comenzaron a proyectarse espacios para albergar las comisarías. El primer edificio construido ex profeso fue sumamente tardío. El arquitecto Federico Mariscal fue el responsable del proyecto para albergar la $6^{a}$ comisaría, ubicada en la esquina de las calles de Revillagigedo y Victoria, inaugurada en 1906.

Sin embargo, la infraestructura policial estuvo lejos de satisfacer las necesidades de vigilancia, detención, elaboración y archivo de los cuantiosos procesos administrativos encargados a la policía. Sumado al rezago de los edificios, la $6^{\text {a }}$ comisaría sufrió severos daños durante la Decena Trágica, cuya reparación fue estimada en más de 60000 pesos y se cargó, descuidando los procedimientos, a la Caja de Ahorros y Préstamos de la

\footnotetext{
48 AHCM, Ayuntamiento de México, Policía, Inspección General y Comisarías, vol. 3651, exp. 36, f. 3. Contrato de arrendamiento de la casa número 24 de la calle de Chiconautla, México D. F., 10 de junio de 1878. El inventario del contrato de arrendamiento de la $4^{a}$ comisaría permite saber que el apero tenía un zaguán con dos chapas, el despacho vidrieras en la ventana, marco y vidrieras en la entrada, chapa y llave en la puerta. La planta alta de la casa tenía un gabinete envidriado con chapa, bastidores de vidrio y una ventana para acceder a la azotea, así como una sala y dos recámaras con cielo raso.
} 
Policía.$^{49} \mathrm{El}$ resto fueron casas distribuidas en otras demarcaciones cuyos contratos no siempre se refrendaban, como sugieren los cambios de domicilio reportados en los directorios municipales. Aunque caería en desuso esta práctica a inicios del siglo xx, algunos funcionarios tenían dos domicilios: el de la comisaría y el particular. Cuando ambos coincidían, ocurrieron con frecuencia conflictos, pues allí vivían los comisarios durante su turno, dándose el caso de algunos que habitaban con sus familias en piezas separadas de su despacho, pero adentro de las comisarías. En tales casos, se confundía lo público con lo privado, alentando la ineficacia continuamente señalada en descripciones sobre los servicios policiales.

A propósito del trajín dentro de las comisarías, una crónica periodística describe cómo eran en el último tercio del siglo xIX. Iluminada con un farol desgastado, se entraba por un pasillo al despacho del comisario, donde había gendarmes que iban y venían custodiando a los detenidos. Los separos estaban llenos, de acuerdo a la información que proveyeron los escribientes al periodista, quien los retrató como "un par de jóvenes [...] cuyas rápidas decisiones son de más trascendencia de lo que a primera vista pudiera imaginarse" ${ }^{50}$ Este tipo de registros ponían en entredicho las persuasiones que apostaban por una burocracia policial moderna y eficiente. Cuando las condiciones de los edificios eran consideradas inaceptables, se rendían informes al inspector general o al gobernador del Distrito Federal. Por

49 AHCM, Ayuntamiento de México, Gobernación, Comisaría de Policía, c. 1, exp. 91, 6 fs. Contrato celebrado con el Sr. Francisco Colom para reconstrucción del edificio de la $6^{a}$ comisaría, México D.F., 31 de julio de 1913. Tan sólo para reflexionar sobre la precariedad de las oficinas policiales, cabe mencionar que cuando la partida presupuestaria para material de escritorio se agotaba, los libros, papel para oficios, tintero, portaplumas, máquinas de escribir y otros artículos se adquirían del peculio de los empleados.

50 "En una comisaría”, La Libertad (18 ago. 1883). La descripción se refiere a la quinta comisaría, ubicada en el cruce de las calles Zarco y Violeta, en la colonia Santa María. 
ejemplo, la casa situada en la calle Estanco de Hombres, destinada para "habitación" de los comisarios de la $3^{\text {a }}$ demarcación, "amenaza[ba] con desplomarse" y fue considerada "inhabitable por su estado ruinoso" ${ }^{51}$ Dada la precariedad del espacio físico no es descabellado imaginar el carácter desorganizado de las burocracias policiales en el desempeño de sus labores. En tal sentido, los informes de los inspectores de comisarías representaron a estos edificios y a su personal como una suerte de colmena disfuncional. Tras una visita a las demarcaciones de policía, resultó que todas las comisarías requerían mantenimiento, muchas de ellas de manera urgente. De la primera se detalló que urgía reparar casi la totalidad de los vidrios, poner puertas, componer los excusados y proveer los focos, pues eran indispensables para las labores nocturnas. De la segunda, los informes señalaron que las galeras de detenidos se encontraban en "pésimas condiciones higiénicas", pues los mingitorios carecían de agua corriente, mientras que las vigas de la tercera estaban vencidas $\mathrm{y}$, por consiguiente, "la vida de los detenidos esta[ba] en inminente peligro". ${ }^{52}$ Por tal motivo, la prensa vertía opiniones que denunciaron a las comisarías por ser "cloacas inmundas de crímenes horrendos y asqueroso prostíbulo" donde se había "folgado con todas las libertades y con todas las desgracias”. ${ }^{53}$

Por su parte, los inventarios de las comisarías realizados en la década de 1920 permiten pensar en el creciente número de empleados que trabajaban en las comisarías, así como atisbar ciertos cambios en las oficinas, donde el personal laboraba en

51 AHCM, Ayuntamiento de México, Gobernación, Comisaría de Policía, c. 1, exp. 95, f. 3 . El comisario de la $3^{\text {a }}$ demarcación pide se le autorice cambiar de habitación, México D.F., 28 de junio de 1913.

52 AHCM, Ayuntamiento de México, Justicia Comisarias, vol. 2717, exp. 2, f. 1. Informe de la visita de inspección general practicada a la $3^{a}$ comisaría, México D.F., 8 de agosto de 1919, exp. 3, f. 1. Informe de la visita de inspección general practicada a la $3^{a}$ comisaría, México D. F., 22 de julio de 1919.

53 "Las comisarías", Redención (8 jun. 1917). 
dos turnos. En el despacho del comisario había dos escritorios, seis sillas, dos sillones giratorios y un par de libreros. Además, había un reloj de pared, escupideras, teléfono y material de escritorio. En otra pieza había ocho escritorios, numerosas sillas, archiveros, una prensa copiadora, ocho máquinas de escribir e igual cantidad de teléfonos más un conmutador. ${ }^{54}$ Había además un vestíbulo, un cuarto para la comandancia así como celdas para los detenidos y dos bodegas. Sólo en algunos casos había gabinetes separados para tomar huellas, fotografías, atender denuncias y levantar las actas de los detenidos.

En síntesis, las representaciones sobre la modernidad de la Sexta Comisaría y, más adelante, sobre el masivo edificio que ocuparía la Inspección General de Policía - construido en 1927 con base en un proyecto de Vicente Mendiola,$-{ }^{55}$ contrastan con el abandono de la mayor parte de las instalaciones ocupadas por la policía. Consecuentemente, el público percibía las comisarías como "cloacas" no sólo por el abandono de los edificios, sino por las relaciones sociales, rudeza e ilegalidades que allí tenían cabida, esto es, al desorden estrictamente físico y poco funcional de las comisarías correspondía también el flujo de prácticas sumamente desprolijas.

\section{ESTIRAR LA LEY: PRÁCTICAS Y NEGOCIACIONES \\ DE LOS EMPLEADOS EN LAS COMISARÍAS}

Resta por último conocer cómo se construyó la autoridad policial en las prácticas cotidianas dentro de las comisarías. Es verdad que los nombramientos en éstas reproducían un protocolo extensivo a diversos cargos públicos. Los comisarios debían

${ }^{54}$ AHCM, Ayuntamiento de México, Inspección General de Policía, Informes

y Correspondencia, c. 1, exp. 32, ff. 1-7. Entrega de la 10 comisaría, México D.F., 13 de febrero de 1925.

${ }^{55}$ AHCM, Planoteca, número de plano 88. Inspección General de Policía y Estación de Bomberos, 1927. 
jurar frente al inspector y ante la Constitución su compromiso para desempeñar el "leal y patriótico" empleo que se les confería. Por medio de dicho ritual, se pretendía dotar de legitimidad y honorabilidad a un cargo que rara vez se apreciaría dentro de esas coordenadas. Era una formalidad que confería gravedad al cargo al exigir un juramento al código político y marco jurídico vigentes. Sin embargo, el incumplimiento de la legislación era moneda corriente en las comisarías.

Vito Alessio Robles, quien se desempeñó como inspector general durante el mandato de Francisco I. Madero, encontró que la mayor parte de los individuos que integraban "el cuerpo de empleados de las comisarías" eran "toscos y groseros" con un público que se veía obligado "a tratar cualquier asunto en esas sucias oficinas, verdaderas pocilgas" donde laboraba "mucha gente deshonesta" ${ }^{56}$ Un vistazo a los informes de los inspectores encargados de supervisar las comisarías, exigirles cuentas para, a su vez, redirigirlas al inspector general, muestra que el incumplimiento de los reglamentos en las policías tanto de calle como de oficina eran más norma que excepción.

¿Había entonces un criterio igual de vigente pero no escrito para destituir o calificar el desempeño de los cargos públicos? En principio pudiera suponerse que el honor -o mejor dicho, la falta de éste-, pues cuando esa cualidad se veía vulnerada, los superiores cesaban a los funcionarios considerados réprobos, sobre todo si trascendía a la prensa escrita y si la opinión pública se ocupaba de algún escándalo, como puede verse en cuantiosos casos. El 20 de julio de 1913, Juan G. Veramendi era comisario de la $7^{\mathrm{a}}$ demarcación de policía. Transcurrieron once meses cuando solicitó una licencia sin goce de sueldo a sus superiores argumentando su necesidad de atender la salud de su achacosa esposa en Guanajuato, ciudad de donde era originario. A tan sólo dos días de separarse temporalmente de su cargo,

${ }^{56}$ Alessio Robles, Memorias y diario, vol. 1, p. 339. 
comenzaron a llegar denuncias al escritorio del inspector general sobre una serie de incidentes que mostraban la "conducta inmoral y deshonesta” de Veramendi. De manera casi paralela, llegó un oficio similar dirigido al despacho del secretario de Gobernación, quien advirtió que eran “muchas las quejas” realizadas por vecinos de la $7^{a}$ demarcación en contra del comisario $C$. Juan G. Veramendi. Justo cuando éste disfrutaba de su licencia, se denunciaron diversos "actos arbitrarios" de los cuales también se ocupaba la prensa. Por tal motivo, se calificaron como "muy justificadas las quejas" y, en aras de corregir a su personal, el inspector recomendó cesar a Veramendi de su empleo en la policía. ${ }^{57}$ Entonces, la toma de protesta que pretendía dotar de honorabilidad al cargo público era un ritual tan solemne como insignificante, toda vez que fluían prácticas ilegales pero sistematizadas, siendo la ley fuga y las torturas dos claros ejemplos. ${ }^{58}$ El caso Veramendi es solamente una pequeñísima muestra de los abusos ejercidos por los comisarios. En este caso, extraer "a palos” su declaración a un labrador de nombre Francisco Cervantes; paliza que ocasionó su muerte. ${ }^{59}$

Así, existen suficientes casos para conocer las gestiones formales e informales de los policías de oficina. A nivel de la calle, los gendarmes cometían atropellos de diversa índole, traficaban favores, vendían la impunidad, extorsionaban y pedían pagos o "mordidas". Es decir, eran el eslabón seminal de la cadena de ilegalidades atizadas por el poder policial. Algo similar puede decirse de la interacción en las comisarías donde, por un lado, se cometían ilegalidades, extorsiones y un variado cúmulo

57 AHCM, Gobernación, Comisaría de Policía, c. 1, exp. 81, 20 de julio de 1913-28 de julio de 1914, f. 4v. "La mujer de Cervantes ha declarado acerca de la muerte de su esposo”, El Diario (25 mar. 1914).

58 Sobre la ley fuga y la tortura policial véase Piccato, A History of Infamy, pp. 107-125.

59 "Un robo, una detención, una camisa de fuerza y al final un cadáver", $E l$ Diario (17 mar. 1914). 
de prácticas que agraviaban a la sociedad urbana. Por otro, los comisarios, subcomisarios y secretarios también intervenían en establecimientos comerciales de diversa índole. En lugar de observar que se cumplieran los reglamentos, a menudo pasaban por alto lo que éstos prescribían o bien amenazaban a los propietarios a cambio de dinero.

Entre las gestiones de escritorio se reiteraban irregularidades relativas al cobro de multas, retiro de licencias a comercios y la liberación de detenidos de las galeras. Este género de "anomalías" se multiplicaron. Por ejemplo, del titular de la $1^{\text {a }}$ demarcación se decía que era "empeñoso en el despacho de sus labores", pero con frecuencia incurría en ilícitos poniendo en libertad a los reos con una simple amonestación. Del oficial de barandilla en la misma comisaría se decía que cometía "irregularidades" suficientes para dudar de su "honorabilidad". ${ }^{60}$ Entre otras recomendaciones, el abogado visitador indicó que el personal de las comisarías debía abstenerse de imponer penas, pues no eran autoridades competentes para ello. En general, se les exhortaba a pedir la asesoría de los jueces auxiliares cuando dudaran o ignoraran los procedimientos. Al respecto, un visitador señaló: "en mi concepto no ha habido por parte de los comisarios un comportamiento doloso, sino una mera ignorancia de sus obligaciones" ${ }^{61}$ A pesar de tal apreciación, los funcionarios amonestados desatendían las recomendaciones y, casi de manera permanente, tuvieron roces y conflictos con los visitadores.

$\mathrm{Al}$ administrar discrecionalmente castigos, las situaciones límite eran las ya mencionadas torturas y la ley fuga. Es cierto que eran medidas extremas que figuraban en las "leyes profanas"

60 AHCM, Ayuntamiento de México, Justicia Comisarias, vol. 2717, exp. 1, f. 8. Informe de la visita de inspección general practicada a la $1^{\mathrm{a}}$ comisaría, México D.F., 16 de julio de 1919.

${ }_{61}$ AHCM, Ayuntamiento de México, Justicia Comisarías, vol. 2717, exp. 5, f. 3. Informe de la visita de inspección general practicada a la $5^{\text {a }}$ comisaría, México D.F., 16 de julio de 1919. 
practicadas por los policías. ${ }^{62}$ Sin embargo, un amplísimo repertorio de castigos ilegales menos violentos o letales se desplegaba en las comisarías. Uno de ellos era imponer trabajos forzados que, en cierta medida, emulaban servicios comunitarios. Generalmente, éstos consistían en obligar a los presuntos infractores a limpiar las calles o los edificios de la policía. Esto era tomado con gravedad por los inspectores que rendían parte sobre la cotidianidad en las comisarías, manifestando que era inaceptable que los comisarios emplearan a los detenidos bajo la pena de arresto para "el aseo de las calles [...] porque eso implica gravamen a la persona señalada” y, añadían, porque para purgar dicha pena se encontraba la cárcel municipal..$^{63}$ En el mismo sentido, un reo manifestó que en los separos le arrojaron varias cubetas de agua porque los gendarmes consideraron que debía calmarse. Diversas sanciones leves pero ilegales de este género tensaron las relaciones de los agentes policiales con los sectores medios y, sobre todo, con los populares y sujetos sin posibilidad de eludir la acción policial mediante el soborno.

Lejos de mitigarse, el manejo inescrupuloso de la policía fue acaso mayor o tal vez más visible en las fuentes durante la posrevolución. Los roces cotidianos con distintos componentes de la sociedad hacían de la policía una instancia particularmente sensible a los conflictos cuyo registro documental da cuenta de incidentes debido a los cuales los comisarios se hacían "odiosos" para los habitantes. Dentro de los sectores que más se manifestaron figuraron comerciantes, como Santos y Porfirio Bárcenas, establecidos en la esquina de Hidalgo e Illescas. Ambos tuvieron

${ }^{62}$ Con "ley de los profanos" es posible referir la dialéctica entre los marcos legales y las prácticas que no lo eran, propias tanto del mundo policial como del hampa. Véase Caimari, "Presentación", pp. 9-21.

${ }^{63}$ AHCM, Ayuntamiento de México, Justicia Comisarías, vol. 2717, exp. 6, f. 1. Informe de la visita de inspección general practicada a la $6^{a}$ comisaría, México D.F., julio de 1919. Además, al emplear a los detenidos en ese tipo de faenas, era común que se cometieran vejaciones, se les insultaba y golpeaba. 
una querella con el secretario de la $5^{\text {a }}$ comisaría, pues aseguraban que una noche se presentó en su establecimiento acompañado de varios agentes, los obligó a abrirlo y cortó los cables telefónicos, cató la tienda y extrajo dinero de la caja fuerte, “ejecutando todos estos actos por propia autoridad". ${ }^{64}$ Debido a la molestia que generó este secretario, el inspector general durante el gobierno convencionista señaló:

Como en mi sentir esos hechos constituyen un abuso de autoridad, una protección de fuga y un atropello a la autoridad por mí representada, ordené al mismo Jefe de la Policía Reservada que practicase la averiguación del caso y consignase las diligencias al juez de instrucción militar en turno por la causa ya dicha de no tener tribunales penales del orden común.

Lo hizo, pero el juez también fue omiso. Luego tuvo conocimiento de que también había robado "cuarenta gallos finos de pelea” y los vendió en Orizaba. Volvió a encargar al jefe de la Reservada que retomara el caso y que entregara al funcionario a la "autoridad competente", pero no lo hizo.

La impunidad era común en casos como el reseñado. Buena parte de los abusos cometidos por empleados de las comisarías fueron exhibidos por la prensa sin enfrentar sanciones ni procesos judiciales. De hecho, pudiera admitirse que se tendieron acuerdos informales para dar soporte a las extorsiones. Por ejemplo, los comisarios recibían “cooperaciones” por parte de los comerciantes que, supuestamente, se destinaban al mantenimiento de los edificios. El de la $8^{a}$ demarcación, reunía en su despacho a dieciocho dueños de casillas de pulque para que, en calidad de "ofrecimiento voluntario", le obsequiaran entre 10

${ }^{64}$ CEHM-CARSO, Manuscritos del Primer Jefe del Ejército Constitucionalista, sección 52, leg. 5741, exp. 6, ff. 1-2. Carta de J. Munguía Santoyo, inspector de Policía, al procurador de Justicia del Distrito Federal, México D.F., 17 de septiembre de 1915. 
y 20 pesos con cierta frecuencia. ${ }^{65}$ Además, se presumía que el personal de la mencionada oficina malversaba fondos públicos.

Cabe recordar que en las comisarías se elaboraban y archivaban los padrones de establecimientos comerciales. Independientemente de si éstos eran precisos o que estuviesen actualizados, eso dotaba de una base de conocimiento empleada lo mismo para conocer la vigencia de las licencias que para tener una imagen de la geografía de los negocios urbanos. La información que tenían los policías, entonces, resultaba bastante conveniente tanto para verificar la legalidad de los comercios como para extorsionar. Sin embargo, no fueron solamente ese tipo de prácticas las que agraviaban a la población de la capital, pues las comisarías eran la primera instancia donde se denunciaban riñas, abusos y robos. Allí llegaban los particulares en demanda de justicia, como Natalia A., quien acusó a Secundino C. - su amante- asegurando que éste la había insultado y golpeado. Pasaron menos de dos horas para que el supuesto agresor fuese liberado después de que su "legítima esposa" concretó un "arreglo particular con un empleado". ${ }^{66}$

En casos excepcionales, el manejo inescrupuloso de las comisarías tenía consecuencias, como el cese de empleados. Cuando el abogado visitador demostró que los libros de registro de reos no concordaban con el número de detenidos en las galeras de

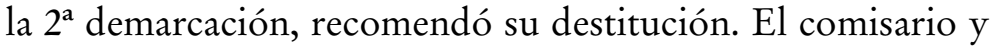
el secretario increparon que "solamente acataban órdenes del inspector General”. En una visita subsecuente efectuada en la madrugada, el visitador aseguró que el comisario se encontraba ebrio, mientras que en la $4^{a}$ y la $7^{a}$ advirtió que estaban "haciendo negocitos". En lugar de consignar a los detenidos para ser

${ }^{65}$ AHCM, Ayuntamiento de México, Justicia Comisarias, vol. 2717, exp. 8, f. 3. Informe de la visita de inspección general practicada a la $8^{a}$ comisaría, México D.F., 16 de agosto de 1919.

${ }^{66}$ AHCM, Ayuntamiento de México, Justicia Comisarías, vol. 2717, exp. 11, f. 16. Padrón de comercios, México D.F., 1o de julio de 1919. 
calificados por el presidente municipal o su representante, los ponían en libertad a cambio de una cuota que oscilaba entre 3 y 10 pesos, dinero que ingresaba a los bolsillos de "comisarios poco escrupulosos" en lugar de recaudarse por la instancia reglamentaria, es decir, la Tesorería Municipal. ${ }^{67} \mathrm{~A}$ episodios aparentemente menudos como los mencionados, se suman trayectorias policiales que, como Valente Quintana, aprovecharon el empleo público para afianzar intereses privados.

Como consecuencia de esas prácticas, se crearon cargos para supervisar a las policías. Si bien la multiplicación de las burocracias policiales se devela como una maraña casi ininteligible, ese tipo de funcionarios obedeció a la intención de equilibrar atribuciones y acotar poderes en el proceso de construcción del Estado. Esto es, debido a su margen de discrecionalidad, la policía exigía contrapesos. En pocas palabras, la creciente burocratización de la fuerza policial, tanto en las comisarías como en la inspección general, obedecía, efectivamente, a la especialización de las labores de oficina pero, de manera destacada, se trató de una estrategia para restringir la autoridad de sus distintas dependencias a la madeja de reglas que normaban su cotidianidad. ${ }^{68}$

Esta cotidianidad también estaba marcada por camaraderías o lo contrario, rivalidades. En su mayor parte, ambas resultaron del hecho de cohabitar, estar en un cuartel o en una oficina diario durante varias horas. ${ }^{69}$ Allí, los empleados no sólo cumplían obligaciones ni seguían las reglas no escritas, sino que pasaban el tiempo jugando cartas, platicaban y fumaban cigarrillos, bebían tanto en oficinas como en despachos de bebidas o, simplemente,

\footnotetext{
${ }^{67}$ AHCM, Ayuntamiento de México, Justicia Comisarias, vol. 2717, exp. 17, ff. 2-3. Informe de la visita de inspección general practicada a la $5^{\mathrm{a}}$ comisaría, México D.F., 12 de agosto de 1921.

${ }^{68}$ En este sentido, sigo la hipótesis formulada por Herbert Reinke para el caso de la policía alemana durante el periodo imperial: LÜDKE y ReInKE, "Crime, Police, and the 'Good Order'”, pp. 119-120.

${ }^{69}$ Emsley, “The Policeman as Worker”, p. 106.
} 
dormían durante sus jornadas laborales. Todo ello comportaba violencias y desacatos. Es decir, era un espacio de trabajo con animosidades y reyertas.

Tal parece que la componenda de este tipo de incidentes se concretó en acuerdos profanos para negociar la autoridad. ${ }^{70}$ Hacia la década de 1920, éstos tendieron a normalizar la extorsión hacia afuera por medio de la llamada mordida y, dentro de las burocracias policiales y los cuerpos de seguridad, muestran el establecimiento de sistemas de cuotas -o "prebostazgo" como decían algunos registros - para dar cauce al flujo ilegal de dinero obtenido de las extorsiones. Sin abundar en más casos, es sugerente cómo la ampliación de agentes de oficina en los servicios policiales incluyó empleados dedicados a inspeccionar las comisarías, cuyos informes permiten conocer con cierto detalle y problematizar el mundo de las burocracias en espacios nodales de la sociedad urbana.

\section{CONCLUSIONES}

En atención al epígrafe citado, cabe decir que los funcionarios consideraban raquíticos sus sueldos y, de alguna manera, justificaban la informalidad de sus prácticas como fuente complementaria de ingresos. Las presiones que experimentaban respondían a una aspiración, pues cotejados con los salarios más bajos, resulta que los empleados en las comisarías pertenecían a la incipiente clase media que, si se percibía a sí misma carente, lo hacía por anhelar un estilo de vida material de difícil acceso. Era entonces "pobre" para los potentados, pero suntuario para esa mayoría que vivía en economía de subsistencia.

El caso de la policía es problemático porque en ésta coexistían sectores acomodados en rangos altos, medios de diversa índole en las oficinas y populares en la base que se desplegaba,

70 Sobre esto véase CaImari, "Presentación". 
cotidianamente, en la calle. Antes de confrontarse, algunos trabajadores de las comisarías manifestaron poco su aspiracionismo, pero sí llegaron a recriminar como injustos sus salarios en relación con el tiempo que dedicaban a sus labores. Todo ello acabaría por hacer del lucro personal parte del oficio. Dentro de los primeros diagnósticos de este ramo de la administración pública, se advertía la "desviación de la ley". ${ }^{71}$

Después de revisar algunas funciones, los salarios y las atribuciones de la burocracia policial resultan una obviedad: la policía no era un monolito, igual que otros sectores de empleados públicos. De manera sugerente, los rangos intermedios en jerarquía también observaron un dinamismo basado en combinar méritos, competencia y cualificación con redes de parentesco, amicales e injerencia de altos funcionarios. Además, fue un sector en que despuntó la autorreflexión sobre el empleo público. No es fortuito que entre las comisarías haya emergido el policía "escritor", al cual lo mismo se le encargaron compilaciones de bandos y diccionarios que iniciativas para dirigir publicaciones periódicas orientadas a generar una identidad gremial o, mejor dicho, un espíritu de cuerpo.

Las condiciones físicas o espaciales de las comisarías estaban lejos de proveer un escenario racionalmente ideado para el trabajo de oficina. De hecho, nada más lejano a la idea de estación de policía que las condiciones que observaban dichos espacios, donde de hecho se hibridaron el despacho público y el domicilio privado del comisario. Así, el poder policial no se desplegaba ni en la práctica ni arquitectónicamente. Lejos de ser engranes asépticos, los comisarios mezclaban intereses particulares con un servicio público y encabezaron un poder desarticuladamente.

Por último, el incremento de empleos tenía que ver con la especialización y, sobre todo, con gestionar información. Todos los cargos que se multiplicaron tuvieron que ver con eso:

71 Mendieta y NúÑEz, La administración pública, p. 138. 
archivistas, telegrafistas, telefonistas, taquígrafos, además de los dedicados a mecanismos de identificación, como médicos practicantes y fotógrafos que, de cualquier modo, generarían más información. Tal tecnificación no oculta que el funcionamiento de la policía porfiriana y posrevolucionaria en la capital del país se apoyó bastante en la informalidad, exhibiendo de alguna manera los límites e, incluso, cierta debilidad para disciplinar a los empleados públicos. De alguna manera, historiar socialmente la policía en la ciudad de México obliga a seguir el doble objetivo planteado en este artículo, es decir, dar rostro social a las burocracias e identificar las transformaciones tanto formales como informales experimentadas por las policías en su proceso de modernización.

\section{SIGLAS Y REFERENCIAS}

AGN Archivo General de la Nación, Ciudad de México, México.

AHCM Archivo Histórico de la Ciudad de México, México.

CEHM-CARSO Centro de Estudios de Historia de México-CARSO, Ciudad de México, México.

PEF Presupuesto de Egresos de la Federación.

UTBC University of Texas-Benson Collection, Texas, Estados Unidos.

Adamovsky, Ezequiel, “'Clase media': problemas de aplicabilidad historiográfica de una categoría”, en AdAmovsky, Visacovsky y VARGas (eds.), 2014, pp. 115-138.

Adamovsky, Ezquiel, Sergio Visacovsky y Patricia Beatriz Vargas (eds.), Clases medias, Buenos Aires, Ariel, 2014.

Agostoni, Claudia, Monuments of Progress: Modernization and Public Health in Mexico City, 1876-1910, Calgary, Boulder, Mexico, University of Calgary Press, University Press of Colorado, Universidad Nacional Autónoma de México, 2003.

Alessio Robles, Vito, Memorias y diario, estudio preliminar de Javier Villarreal Lozano, México, Porrúa, 2013, 3 volúmenes. 
Barbosa Cruz, Mario, “Los empleados públicos, 1903-1931”, en Barbosa e ILLADES, 2013, pp. 117-154.

Barbosa Cruz, Mario, "Empleados públicos en la ciudad de México: condiciones laborales y construcción de la administración pública (1903-1931)”, en Remedi y Barbosa Cruz (comps.), 2014, pp. 129-150.

Barbosa Mario y Carlos Illades (eds.), Los trabajadores de la ciudad de México, 1860-1950, México, El Colegio de México, 2013.

Barrera Bassols, Jacinto, El caso Villavicencio: violencia y poder en el Porfiriato, México, Alfaguara, 1997.

Berlière, Jean-Marc, Catherine Denys, Dominique Kalifa y Vincent Milliot (dir.), Métiers de police. Etre policier en Europe XVIIIe-XXe siècle, Rennes, Presses Universitaires de Rennes, 2008.

BRETAs, Marcos L., Ordem na cidade. O exercício cotidiano da autoridade policial no Rio de Janeiro: 1907-1930, traducción de Alberto Lopes, Río de Janeiro, Rocco, 1997.

Caimari, Lila, “Presentación”, en La ley de los profanos. Delito, justicia y cultura en Buenos Aires (1870-1940), Buenos Aires, Fondo de Cultura Económica, 2007, pp. 9-21.

Caimari, Lila y Máximo Sozzo (eds.), Historia de la cuestión criminal en América Latina, Rosario, Prohistoria Ediciones, 2017.

CÁrdenas Muñoz, Vania, El orden gañán. Historia social de la policía: Valparaíso, 1896-1920, Concepción, Ediciones Escaparate, 2013.

Dávalos, Marcela, Regina Hernández Franyuti y Diego Pulido Esteva (eds.), Orden, policía y seguridad: historia de las ciudades, México, Instituto Nacional de Antropología e Historia, 2017.

DAvis, Diane E., "Historia de detectives: rastreando a la policía de la capital en la historiografía política de México”, en Rodríguez Kuri y Tamayo, 2004, pp. 69-94.

Deluermoz, Quentin, “Présence d’État. Police et société à Paris (1854-1880)”, en Annales. Histoire, Sciences Sociales, 64: 2 (mar.-abr. 2009), pp. 435-462. 
Dublán, Manuel y José María Lozano, Legislación mexicana o colección completa de las disposiciones legislativas, México, Imp. del Partido Liberal, 1876-1912, 42 tomos.

Emsley, Clive, "The Policeman as Worker: A Comparative Survey c. 18001940", en International Review of Social History, 45 (2000), pp. 89-110.

Emsley, Clive y Louis A. Knafla (eds.), Crime History and Histories of Crime: Studies in the Historiography of Crime and Criminal Justice in Modern History, Westport, London, Greenwood Publishing Group, 1996.

Finnane, Mark, “The Origins of 'Modern' Policing”, en Knepper y JohanSEN (eds.), 2016, pp. 456-473.

Foucault, Michel, "El polvo y la nube", en J. LÉOnard, La imposible prisión: debate con Michel Foucault, traducción de Joaquín Jordá, Barcelona, Anagrama, 1982, pp. 37-54.

Galeano, Diego, “Genealogía del comisario: policía y orden urbano en Buenos Aires”, en Iberoamericana, xvII: 64 (2017), pp. 13-33.

Gómez Galvarriato, Aurora y Aldo Musacchio, "Un Nuevo índice de precios para México, 1886-1929”, en El Trimestre Económico, 67: 1 (ene.-mar. 2000), pp. 47-91.

Gómez Llata, Indalecio, Diccionario de policía, México, David Camacho Editor y Agente, 1904.

González Navarro, Moisés, El porfiriato. La vida social, vol. 4, Historia moderna de México, México, Hermes, 1957.

Kalifa, Dominique, "L'homme de l'entre-deux. L’identité brouillé du commissaire de police au XIX siècle”, en Kalifa y Karila-Cohen (eds.), 2008, pp. 7-23.

Kalifa, Dominique y Pierre Karila-Cohen (eds.), Le commissaire de police au XIXe siècle, París, Publications de la Sorbone, 2008

Knepper, Paul, y Anja Johansen (eds.), The Oxford Handbook of the History of Crime and Criminal Justice, Oxford, Oxford University Press, 2016.

Lomnitz, Claudio, El primer linchamiento de México, México, El Colegio de México, Columbia University Center for Mexican Studies, 2015. 
LÜDKE, Alf y Herbert ReInke, “Crime, Police, and the 'Good Order': Germany”, en EMSLEy y KNAFLA (eds.), 1996, pp. 109-133.

Mendieta y NúÑez, Lucio, La administración pública en México, México, Imprenta Universitaria, 1942.

Nacif Mina, Jorge, La policía en la historia de la cindad de México, México, Departamento del Distrito Federal, 1986.

Orijel Serrano, Ivette, “Escenas ciudadanas del descontento. Quejas, demandas, denuncias y protestas de los sectores medios urbanos en la ciudad de México, 1892-1910", tesis de doctorado en historia, Universidad Nacional Autónoma de México, 2016.

Palma Alvarado, Daniel (ed.), Delincuentes, policías y justicias en América Latina, siglos XIX Y XX, Santiago de Chile, Universidad Alberto Hurtado, 2015.

Piccato, Pablo, A History of Infamy: Crime, Truth, and Justice in Mexico, Oakland, University of California Press, 2017.

Piccato, Pablo, Ciudad de sospechosos: crimen en la ciudad de México, 1900-1931, traducción de Lucía Rayas, México, Centro de Investigaciones y Estudios en Antropología Social, 2010.

Pilbeam, Pamela M., The Middle Class in Europe 1789-1914: France, Germany, Italy, and Russia, Londres, MacMillan, 1990.

Pulido Esteva, Diego, "Los gendarmes: perfil social de la policía capitalina, 1900-1930”, en Dávalos, Hernández Franyuti y Pulido Esteva (eds.), 2017, pp. 179-202.

Quevedo y ZubIeta, Salvador, La camada: novela histórica mexicana, México, Librería de Charles Bouret, 1912.

Quiroz, Enriqueta, "Vivir de un salario: el costo del consumo doméstico", en Salmerón y Aguayo (coords.), 2013, pp. 119-136.

Remedi, Fernando Javier y Mario Barbosa Cruz (comps.), Cuestión social, políticas sociales y construcción del Estado social en América Latina, siglo XX, Córdoba, México, Centro de Estudios Históricos Prof. Carlos S. A. Segreti, Universidad Autónoma Metropolitana-Cuajimalpa, 2014. 
Rodríguez Kuri, Ariel, Historia del desasosiego. La revolución en la ciudad de México, 1911-1922, México, El Colegio de México, 2010.

Rodríguez KuRI, Ariel y Sergio TAMayo, Los primeros cien años: los próximos cien, México, Universidad Autónoma Metropolitana-Azcapotzalco, 2004.

Rohlfes, Laurence J., "Police and Penal Correction in Mexico City, 18761911: A Study of Order and Progress in Porfirian Mexico", tesis doctoral, Nueva Orleans, Tulane University, 1983.

Salmerón, Alicia y Fernando Aguayo (coords.), "Instantáneas" de la ciudad de México: un álbum de 1883-1884, México, Instituto Mora, 2013.

Sánchez García, Juan Hugo, "Los guardianes de Oaxaca”, en Dávalos, Hernández Franyuti y Pulido Esteva (eds.), 2017, pp. 117-148.

Santoni, Pedro, "La policía de la ciudad de México durante el Porfiriato: los primeros años (1876-1884)", en Historia Mexicana, xxxIII:1 (129) (jul.-sep. 1983), pp. 97-129.

Speckman, Elisa, Crimen y castigo. Legislación penal, interpretaciones de la criminalidad y administración de justicia (ciudad de México, 1872-1910), México, El Colegio de México, Universidad Nacional Autónoma de México, 2002.

Vanderwood, Paul J., Desorden y progreso: bandidos, policías y desarrollo mexicano, traducción de Félix Blanco, México, Siglo Veintiuno Editores, 1986. 